\title{
Does a self-referral counselling program reach doctors in need of help? A comparison with the general Norwegian doctor workforce Karin E Isaksson Rø*1,2, Tore Gude ${ }^{1,2}$ and Olaf G Aasland ${ }^{3}$
}

\author{
Address: ${ }^{1}$ Department of Behavioural Sciences in Medicine, Institute of Basic Medical Sciences, Faculty of Medicine, University of Oslo, Norway \\ Postbox 1111 Blindern, 0317 Oslo, Norway, ${ }^{2}$ The Research Institute, Modum Bad, 3370 Vikersund, Norway and ${ }^{3}$ The Research Institute, The \\ Norwegian Medical Association, Postbox 1152 Sentrum, 0107 Oslo, Norway and Institute of Health Management and Health Economics, \\ University of Oslo, Postbox 1111 Blindern, 0317 Oslo, Norway \\ Email: Karin E Isaksson Rø* - k.e.i.ro@medisin.uio.no; Tore Gude - tore.gude@medisin.uio.no; \\ Olaf G Aasland - olaf.aasland@legeforeningen.no \\ * Corresponding author
}

Published: 16 March 2007

BMC Public Health 2007, 7:36 doi:10.1 I86/147I-2458-7-36
Received: 7 October 2006

Accepted: 16 March 2007

This article is available from: http://www.biomedcentral.com/I47/-2458/7/36

(C) 2007 Rø et al; licensee BioMed Central Ltd.

This is an Open Access article distributed under the terms of the Creative Commons Attribution License (http://creativecommons.org/licenses/by/2.0), which permits unrestricted use, distribution, and reproduction in any medium, provided the original work is properly cited.

\begin{abstract}
Background: Doctors have a relatively high degree of emotional distress, but seek help to a lesser degree and at a later stage than other academic groups. This can be deleterious for themselves and for their patients. Prevention programs have therefore been developed but it is unclear to what extent they reach doctors in need of help. This study describes doctors who participated in a selfreferrral, easily accessible, stress relieving, counselling program in Norway, and compares them with a nationwide sample of Norwegian doctors.

Methods: Two hundred and twenty seven (94\%) of the doctors, 117 women and 110 men, who came to the resort centre Villa Sana, Modum, Norway, between August 2003 and July 2005, agreed to participate in the study. Socio-demographic data, reasons for and ways of help-seeking, sickleave, symptoms of depression and anxiety, job stress and burnout were assessed by self-reporting questionnaires.

Results: Forty-nine percent of the Sana doctors were emotionally exhausted (Maslach) compared with $25 \%$ of all Norwegian doctors. However, they did not differ on empathy and working capacity, the other two dimensions in Maslach's burnout inventory. Seventy-three percent of the Sana doctors could be in need of treatment for depression or anxiety based on their symptom distress scores, compared with 14\% of men and 18\% of women doctors in Norway. Twenty-one percent of the Sana doctors had a history of suicidal thoughts, including how to commit the act, as compared to $10 \%$ of Norwegian doctors in general.

Conclusion: Sana doctors displayed a higher degree of emotional exhaustion, symptoms of depression and anxiety as well as job related stress, compared with all Norwegian doctors. This may indicate that the program at Villa Sana to a large extent reaches doctors in need of help. The counselling intervention can help doctors to evaluate their professional and private situation, and, when necessary, enhance motivation for seeking adequate treatment.
\end{abstract}




\section{Background}

Emotional distress and impaired function among doctors can be deleterious for patients, as well as for the doctors themselves, their colleagues, other co-workers and families [1-3]. Doctors have a relatively high prevalence of depression, as well as higher suicide rates compared to other academic groups [4-8], and possibly also an increasing prevalence of burn-out [9]. Whereas these facts should lead to early helpseeking, doctors seem to seek help to a lesser degree, and later in the course of disease than do other groups $[10,11]$. Doctors do not easily adapt to the patient role and they also have problems being professional when treating a colleague $[12,13]$. Especially regarding mental health problems, doctors tend to be passive, embarrassed to seek help and worried about lack of confidentiality $[2,14]$. The term "hazardous heroes" has been used about doctors going to work with symptoms and problems for which they would have given their patients sick-leave [15].

Internationally it has been observed that doctors obtain treatment late in the course of emotional distress; many have been prompted by third parties such as insurance companies, police and review boards, which indicates that job performance has been impaired $[16,17]$. Treatment programs have with some success tried to lower the threshold for seeking treatment by letting the doctors use pseudonyms $[16,18]$, offering treatment at one centralized national hospital in order to avoid the local environment [19], and by ensuring complete confidentiality, easy access and offices not identifiable with psychiatry $[20,21]$.

The conditions described above have also led to the establishment of preventive programs. Primary and secondary preventive interventions for doctors have focused on developing appropriate stress management and coping skills [22-24]. Possible effects of such programs on emotional distress need further documentation. It is also important to explore the characteristics of the doctors recruited to such programs. Do the programs really reach doctors in need of help? To answer this, one needs to compare the help seeking group with the general doctor population. Few studies of this kind have been performed, and none in Norway.

In 1998, the Norwegian Medical Association (NMA) established a short-term counselling program for doctors, called Villa Sana. The declared aims for this effort were to enhance health and life quality, strengthen professional awareness and identity and prevent burnout. A prospective study of sociodemographic and clinical characteristics of doctors entering this program over a two-year period from August 2003 was initiated. The questionnaires were chosen in order to make the data comparable to those from a nationwide sample of Norwegian doctors. In this paper, we have raised the following research questions:

1. What characterizes doctors who seek help at Villa Sana with regard to gender, age and speciality compared to all Norwegian doctors?

2. a) How do doctors apply for help at Villa Sana, and what reasons do they give for seeking help?

b) To what degree did they seek help before coming to Villa Sana?

3. Do doctors seeking help at Villa Sana differ from Norwegian doctors concerning degree of job stress, burnout and symptoms of depression and anxiety?

\section{The Villa Sana program}

The program offers two kinds of interventions for doctors or doctors with partners, who feel the need to reflect on their situation, related either to professional or private matters or both. One is a single day counselling session with one counsellor if the doctor comes alone, or two counsellors when there is also a partner or a spouse. The session lasts for 6-7 hours, aiming to give time and possibility to discuss the doctor's life situation and to suggest steps needed to handle the situation. This can include advice on seeking formal medical treatment including psychotherapy. The other type of intervention is a groupbased, week-long course with boarding, dimensioned for eight individual doctors or four couples. There are daily lectures, group discussions and physical activity. One individual counselling session is offered during the week. Themes for the lectures are: possibilities and restraints in working life, the individual's resources and personality, concepts of identity, family relations, communication, team work and prevention of burnout. The group discussions are based on the participants' own experiences, providing the possibility to share these issues with colleagues.

The idea behind Villa Sana was that the program should be easily accessible. This includes making contact procedures as simple as possible, having readily available times for counselling appointments and having few restrictions as to reasons for contact. Doctors can contact Villa Sana directly on the phone, by post or by e-mail for an appointment. No referral is needed. All applicants are welcomed, except when need for immediate medical treatment is obvious, like serious risk for suicide or psychotic breakthrough. The program has been presented in the Norwegian Medical Journal and is announced twice a year in the same Journal. There are internet links to Villa Sana from the Norwegian Medical Association's web pages, as well as from Modum Bad's web pages. Members of the staff at 
Villa Sana are also invited to different physician meetings to inform about the program.

The Norwegian Medical Association covers all expenses, including travelling costs, making it possible for doctors from all parts of Norway to use Villa Sana. Since the program is defined as a preventive and not a clinical intervention, no medical records are kept.

\section{Methods}

Of 242 eligible doctors, who participated in the Villa Sana programs between August 2003 and July 2005, 227 doctors $(94 \%)$ gave their informed, written consent to participate in the study. Eighty-two percent $(\mathrm{n}=187)$ came for a counselling session and $18 \%(n=40)$ took part in the course program. The Sana doctors are compared with data from a survey of health, work conditions and life quality of Norwegian doctors from 1993 [25], comprising from $1009-6600$ doctors depending on the object of inquiry.

\section{Specialities are grouped into}

non-specialist, general practice (GP), internal medical specialities, surgical specialities, psychiatric specialities, public health and laboratory medicine [25].

\section{Ways of help-seeking}

There are five dichotomous categories (0-no, 1-yes). If more than one category is marked yes, only one is chosen, ranking "referral" highest, "prompting by a colleague" second, "the doctor's own initiative" third, "coming because partner asked them to" fourth and "other reasons" fifth.

\section{Reason(s) for help-seeking}

are defined as one or more of the following areas: health and life quality, exhaustion/burnout, professional identity (meaning identification with the role as a doctor) [26], work-related conditions, private relations and "other reasons" with an option for free text. Specified reasons under "other" were all, except one, possible to categorize under one of the first five areas - hence "other" is in the following omitted. Reasons are scored on a five-point scale (0- not decisive for help-seeking to 4-decisive for help-seeking). Scores 3 or 4 were considered "weighty reason".

\section{Job stress}

A 26 items version of the original 43 items Cooper's job stress questionnaire [27], was used. Responses were given on a five-point scale with $1=$ no stress and $5=$ very much stress. This reduction was based partly on a Principal Component Analysis of data from a Norwegian student/ doctor cohort from 1993 [28] yielding a 17-item version, and partly on the inclusion of nine other relevant items from the original instrument, amounting to 26 items (Cronbach's $\alpha=.90$ ) with three subscales: emotional stress (10 items, $\alpha=.83$ ), fear of litigation ( 6 items, $\alpha$ $=.85)$, and social job-stress including time stress (10 items, $\alpha=.83$ ).

\section{Burnout}

Maslach's Burnout Inventory (MBI), with three sub-scales, was used - emotional exhaustion (10 items), reduced empathy ( 8 items), and reduced work capacity ( 7 items) $[3,29]$. Scores were given on a five-point scale $(1-$ does not fit, 5 - fits very well) evaluating the last two weeks of work. Reduced work capacity is presented with a reverse scale, so that a high value means low capacity. The dimensions are dichotomized in high and low, with cut-off $>3$ called case [3].

\section{General measure of depression and anxiety}

Hopkin's symptom check list 5 (SCL-5) [30]was used. Answers were given on a five-point scale ( 1 - not at all, 5 - very much) evaluating the last two weeks. Studies on SCL-5 presented in literature, have used a four-point scale (1-not at all, 4-very much), with a cut-off of 1.67 for men and 1.75 for women indicating psychiatric case-ness/need for treatment [31]. Multiplying our cut-offs with 5/4 can give a case-estimate based on the five-point scale, yielding a cut-off of 2.09 for men and 2.19 for women. (Moum T, personal communication).

\section{Suicidal disposition}

Measured by three of Paykel's five items [32]: "Have you ever had thoughts about taking your own life?", scored on a five-point scale ( 0 - never, 4 - very often), "Have you ever seriously considered taking your own life with plans on how to do so?" and " Have you ever attempted to commit suicide?"(both scored 0 - no and 1- yes).

\section{Sick leave}

On sick-leave now (0-no, 1-on full-time sick-leave, 2- on part-time sick-leave, 3-full-time rehabilitation or disability leave, 4 - part-time rehabilitation or disability leave, 5 -on retirement).

\section{Present contact with GP}

(0-no, 1-yes)

\section{Present contact with psychiatrist or psychologist} (0-no, 1-yes)

\section{Control samples}

Due to the ten year gap between the 1993 survey and our study, we also investigated possible differences in comparable measurements with a nationwide medical student cohort followed from end of medical school (1993) throughout internship and residency (2003). The cohort is described by Tyssen et al [28], but the 10-year follow-up data from 2003 are not yet publicised (Røvik Jan Ole, per- 
sonal communication). Controlled regarding gender and age, there were no significant differences on Hopkin's Symptom Check list (SCL5) nor on the dimension of emotional exhaustion (MBI) between the young doctor cohort in 2003 and all Norwegian doctors surveyed in 1993. Job stress showed a statistically significant, higher level in 2003, caused by the subdimension emotional stress: 1.97 (95\% Confidence Interval [CI] 1.88-2.06) for 2003 versus 1.72 (95\% CI 1.68-1.74) in 1993, p < 0.001 . The two other job stress dimensions did not differ significantly. Suicidal measures were lower in 2003, but reported as last year's incidence, as opposed to life-time prevalence in 1993.

In addition, we have used general statistical data from the Norwegian Medical Association for 2004 and 2005, including doctors $<70$ years (NMA web site).

\section{Statistics}

Means, correlations, Students' t-test, Chi-square, ANCOVA, Logistic and Linear Regression Analysis were used, with the statistical program SPSS 13.0.

The study is approved by the Regional Ethical Committee for Ethical Research in the South of Norway and by the Data Inspectorate through the Norwegian Social Science Data Services.

\section{Results}

\section{Gender, age and speciality}

There were 117 (52\%) women and 110 (48\%) men in the Sana sample. For comparison on gender, age and special- ity between the Sana-population and Norwegian doctors, see Table 1.

The proportion of GPs was significantly higher in the Sana population (Odds Ratio $(\mathrm{OR})=1,67$ 95\% Confidence Interval (CI) 1.20 to $2.32 \mathrm{p}=0.002$ ), whereas other speciality differences between the two samples were not significant, when controlled for age and gender.

\section{Help-seeking}

Fourty-five percent of the doctors came to Villa Sana on their own initiative, $37 \%$ reported that they were prompted by a colleague, 10\% were referred, $6 \%$ came because they were asked by their partner and 2\% came "for other reasons", without gender or age differences.

Weighty reasons for contacting Villa Sana are presented in Table 2. Most doctors state that health and life quality and exhaustion were weighty reasons for coming. More women than men stated exhaustion, and more men than women came for private reasons. Problems with professional identity were reported by $46 \%$ (95\% CI 27-55) of those younger than 40 years, by $30 \%$ (95\% CI 21-39) for those between 40-50 years and by 19\% (95\%CI 10-27) for those over 50 years of age. There is a significant difference between the youngest and the oldest group ( $\mathrm{p}<$ $0.01)$.

Among the Sana doctors two were recipients of $100 \%$ and four of $50 \%$ rehabilitation or disability benefits, and one doctor was retired. Among the remaining doctors $(\mathrm{N}=$ 219, one person not having answered) 41\% (95\% CI 3347) were on sick-leave at the time of their first visit, with

Table I: Demographic data comparing Sana-doctors, Norwegian doctors I993 and Norwegian doctors 2004/2005.

\begin{tabular}{|c|c|c|c|c|}
\hline & $\begin{array}{c}\text { Sana-doctors } \\
\text { Mean }(95 \% \mathrm{Cl}) \\
\text { Percentage }(95 \% \mathrm{Cl}) \\
\mathrm{n}=226\end{array}$ & $\begin{array}{c}\text { Norwegian doctors } 1993 \\
\text { Mean }(95 \% \mathrm{Cl}) \\
\text { Percentage }(95 \% \mathrm{Cl}) \\
\mathrm{n}=6602\end{array}$ & Sign. & $\begin{array}{c}\text { Norwegian doctors } \\
2004 / 2005 * \\
\text { Mean Percentage } \\
n=17500\end{array}$ \\
\hline \multicolumn{5}{|l|}{ Age (years) } \\
\hline The whole population & $46.9(31.9-67.2)$ & $42.5(23.9-60.7)$ & $\mathrm{p}<0.001$ & 45 \\
\hline Men & $49.7(32.0-67.3)$ & $44.0(25.4-62.6)$ & $p<0.001$ & \\
\hline Women & $44.3(28.2-60.4)$ & $38.9(21.5-56.3)$ & $p<0.001$ & \\
\hline \multicolumn{5}{|l|}{ Gender (\%) } \\
\hline Men/Women & $48(42-55) / 52(45-58)$ & $71(70-72) / 29(28-30)$ & $\mathrm{p}<0.001$ & $64 / 36$ \\
\hline \multicolumn{5}{|l|}{ Specialities (\%) } \\
\hline Non-specialist & $30(24-36)$ & $42(40-43)$ & $P=0.001$ & 45 \\
\hline General practice & $22(17-28)$ & $14(13-15)$ & $p=0.001$ & 13 \\
\hline Internal medical specialities & $16(|I-2|)$ & $15(14-16)$ & ns & 15 \\
\hline Surgical specialities & $15(10-19)$ & $14(13-15)$ & ns & 14 \\
\hline Psychiatric specialities & $8(5-12)$ & $6(5-7)$ & ns & 6 \\
\hline $\begin{array}{l}\text { Others (including social } \\
\text { medicine and laboratory } \\
\text { specialities) }\end{array}$ & $8(5-12)$ & $9(8-10)$ & ns & 8 \\
\hline
\end{tabular}

*Data from the Norwegian Medical Association. Doctors $<70$ years. 
Table 2: Reasons for seeking help.

\begin{tabular}{|c|c|c|c|}
\hline $\begin{array}{l}\text { Weighty reasons for helpseeking } \\
(>2 \text { on a scale from } 0-4)\end{array}$ & $\begin{array}{c}\text { Total } \\
\%(95 \% \mathrm{Cl}) \\
n=224\end{array}$ & $\begin{array}{c}\text { Men/Women } \\
\%(95 \% \mathrm{Cl}) \\
n=108 / 116\end{array}$ & Sign. \\
\hline Health and life quality & $68(62-74)$ & $67(58-76) / 69(60-77)$ & ns \\
\hline Exhaustion/Burn-out & $61(55-68)$ & $52(42--61) / 69(60-77)$ & $P=0.01$ \\
\hline Private relations & $56(49-62)$ & $65(56-74) / 48(39-57)$ & $P<0.05$ \\
\hline Work-related conditions & $44(38-51)$ & $4 \mid(3 I-50) / 46(37-55)$ & ns \\
\hline Professional identity & $28(22-34)$ & $25(17-33) / 31(23-39)$ & ns \\
\hline
\end{tabular}

Proportions of doctors presenting each of the following reasons as a weighty reason for coming to Villa Sana. (Each doctor can present one or more reasons).

significant gender differences: $49 \%$ (95\% CI 40-58) women (including 5 doctors on part-time sick-leave) versus $32 \%$ (95\%CI 23-41) men (including 4 doctors on part-time sick-leave) $\mathrm{p}<0.05$. Age did not influence the proportion of doctors on sick-leave.

Thirty-nine percent had a present GP- contact, and 20\% were in therapy with a psychiatrist or a psychologist when contacting Villa Sana.

\section{Distress assessments}

The comparison between the Sana doctors and all Norwegian doctors regarding distress assessments showed that Sana doctors had significantly higher levels of emotional exhaustion (MBI), depression and anxiety (SCL5), all job stress dimensions and suicidal thoughts controlled for age and gender (Table 3). They did not have higher levels of reduced empathy or reduced work capacity (MBI).

In the Sana group, $49 \%$ (95\% CI 43 to 56) were defined as "cases" on the dimension of emotional exhaustion (MBI), compared to $25 \%$ (95\% CI 22 to 28 ) among Norwegian doctors $(\mathrm{p}<0.001)$.
Concerning SCL-5, cases with scores above cut-off and thus possibly in need of treatment were 73\% (95\% CI 64 to 81 ) among male Sana doctors versus $14 \%$ (95\% CI 1217) among Norwegian male doctors. Among women, $73 \%$ (95\% CI 65-81) of the Sana doctors compared with $18 \%$ (95\% CI 14-22) among Norwegian doctors scored above cut-off ( $\mathrm{p}<0.001$ for both men and women).

Twenty-one percent (95\% CI 15 to 26) of Sana doctors compared to $10 \%$ ( $95 \%$ CI 8 to 12 ) of all Norwegian doctors had seriously considered suicide, as well as having planned it $(\mathrm{p}<0.001)$. Concerning attempted suicide, $2.6 \%$ (95\% CI 0.6 to 4.7 ) of Sana-doctors compared to $1.6 \%$ (95\% CI 0.8 to 2.3 ) of Norwegian doctors reported this (non significant difference).

\section{Discussion}

One of the main findings in this study is the high level of distress among the Sana doctors compared with all Norwegian doctors, assessed with regard to emotional exhaustion, symptoms of depression and anxiety (SCL5 and suicidal thoughts and plans) and job stress parameters. Data indicate that $73 \%$ of the doctors coming to Villa

Table 3: Comparison of burnout, SCL-5, job stress and suicidal thoughts between Sana-doctors and Norwegian doctors 1993.

\begin{tabular}{|c|c|c|c|}
\hline & $\begin{array}{c}\text { Sana-doctors } \\
\text { Estimated Marginal Mean } \\
(95 \% \mathrm{Cl} \text { of standard error })\end{array}$ & $\begin{array}{l}\text { Norwegian doctors } 1993 \\
\text { Estimated Marginal Mean } \\
\text { (95\% Cl of standard error) }\end{array}$ & Sign. \\
\hline $\mathrm{MBI}$ - emotional exhaustion $(\mathrm{I}-5)$ & $3.11(3.00-3.22)$ & $2.52(2.46-2.57)$ & $\mathrm{p}<0.001 \ddagger$ \\
\hline $\mathrm{MBI}$ - reduced empathy $(\mathrm{I}-5)$ & $1.96(1.89-2.03)$ & $1.92(1.89-1.96)$ & ns $\dagger \neq$ \\
\hline $\mathrm{MBI}$ - reduced capacity $(\mathrm{I}-5)$ & $2.31(2.25-2.37)$ & $2.45(2.42-2.48)$ & $p<0.001 \ddagger$ \\
\hline SCL-5 (I-5) & $2.9 \mathrm{I}(2.8 \mathrm{I}-3.0 \mathrm{I})$ & $1.55(1.50-1.60)$ & $P<0.001$ \\
\hline Job stress: Total $(I-5)$ & $2.51(2.42-2.60)$ & $2.02(1.99-2.05)$ & $p<0.001 \ddagger$ \\
\hline Job stress: Emotional (I-5) & $2.19(2.08-2.29)$ & $1.70(1.66-1.73)$ & $p<0.001 \ddagger$ \\
\hline Job stress: Social (I-5) & $2.88(2.78-2.98)$ & $2.28(2.25-2.3 \mathrm{I})$ & $p<0.001 \ddagger$ \\
\hline Job stress: Fear of litigation $(I-5)$ & $2.28(2.17-2.39)$ & $2.12(2.08-2.15)$ & $p<0.01 \ddagger$ \\
\hline Suicidal thoughts $(0-4)$ & $1.19(1.08-1.30)$ & $0.54(0.49-0.60)$ & $\mathrm{p}<0.001 \ddagger$ \\
\hline
\end{tabular}

Controlled for gender and age.

n for Sana $=222-227, \mathrm{n}$ for Norwegian doctors 19931070 - for MBI and SCL-5, 1009 for suicidal thoughts, and 2497 for job stress.

For significant independent gender effect $p<0.01=\dagger$

For significant independent age effect $p<0.01=\ddagger$ 
Sana could be in need of treatment. The program thus reaches doctors who potentially are in serious need of help. Villa Sana being easily accessible, and the fact that the institution is not part of the ordinary medical services, probably facilitates help-seeking. The program seems to be a way of coming into contact with emotionally distressed doctors, where counselling can help them to evaluate their professional and private situation, in addition to enhancing their motivation for treatment, when necessary. Given the reluctance among doctors to ask for help $[10,11]$, such motivation is probably important in a process of seeking adequate professional treatment.

Emotional exhaustion has, according to Falkum [3], been viewed by most authors as the primary dimension in a subsequent development of burnout. The apparent discrepancy in the Sana doctors between reporting high levels of emotional exhaustion, and at the same time not demonstrating reduced empathy or work capacity, is interesting, suggesting either that they take action in time to prevent burnout or stay working as "hazardious heroes", even with considerable distress, in order to fulfill their obligations and to maintain their self-esteem. Two recent studies have found a relationship between burnout dimensions and self-perceived sub-optimal patient care or medical mistakes, one of them suggesting a reciprocal cycle of the one triggering the other [33,34]. These studies, consonant with our findings, point to the importance of burnout prevention, both for the doctors' and their patients' well-being. More research concerning these relationships is needed [35].

Most of the doctors seeking help at Villa Sana present health issues, exhaustion and burnout as weighty reasons for coming. This is in line with the aims of the program, since it was established for potentially exhausted doctors. Among the younger doctors, problems with professional identity were found to be an important reason for helpseeking. This is consonant with a Finnish study, in which plans for changing career were associated with burnout especially among young doctors [36], as well as a study from the United States where career satisfaction showed a strong inverse relationship to burnout [33]. The early phases of the career, before speciality choices have been made, may be a period in which some doctors could benefit from counselling.

Although some studies indicate that female doctors have a higher prevalence of depression or minor psychiatric disease than male doctors $[2,5,6,37]$, women doctors have not been found to have a higher degree of help-seeking than men $[21,38]$. The help-seeking studies however, refer mainly to younger doctors, whereas there are indications of increasing mental distress with age among women doctors, at least in the United Kingdom [6]. This might explain the higher proportion of women at Villa Sana. The issue of confidentiality could also be more important for women than for men [14], and Villa Sana provides a more confidential setting than ordinary psychiatric treatment.

The relative over-representation of GPs in the Sana group indicates that also Norwegian GPs experience more stress than other specialists, as found elsewhere $[36,39,40]$.

Of the doctors who were already in therapy when contacting Villa Sana, many, according to our experience, wanted to discuss aspects of work. We have no registration of the intensity or type of therapy offered to these doctors and there might be several reasons for contacting Villa Sana while in therapy. One possibility is that some therapists and/or doctors view Villa Sana as a place of competence regarding problems related to doctors' work.

The comparative data used were collected ten years prior to our study, which is a limitation to interpreting the results. On the other hand, a more recent study in 2003 of Norwegian doctors, demonstrates that there is little difference between doctors in 1993 and 2003 on some important measures relevant to this study, indicating that the level of distress and mental health problems among Norwegian doctors has not changed dramatically over this period.

Another limitation is the self-reported information, including possible influence of distress symptoms on selfassessment of empathic aptitude and work capacity. The comparable data and studies referred to also use selfreporting forms, thus validating the comparison. There is, however, great need for a more objective evaluation of the relation between self-assessment and objective assessment as underlined in a recent review-article [41].

The major strength of this study is that it recruits a group of doctors seeking help at a counselling program, few studies of this kind having been done previously. The possibility to compare the help-seeking group with Norwegian doctors in general strengthens the design. The prospective aspect of the study enables us to follow the course of distress in the Sana doctors, one and three years after the short-term intervention they have been offered, and to document further help-seeking patterns.

\section{Conclusion}

In comparison with all Norwegian doctors, this study shows high levels of emotional exhaustion, symptoms of depression and anxiety and job-related stress in doctors coming to an easily accessible, short term counselling program. In view of doctors' general reluctance to seek treatment, it is important to document that making a program easily accessible seems to be a way of reaching doctors in 
need of help. The counselling intervention can help doctors to evaluate their professional and private situation, and, when necessary, enhance motivation for treatment. Our prospective study will have the potential to document whether distress levels are reduced with time, and whether advice to seek treatment, given during the Sana intervention, is followed.

\section{Abbreviations \\ Norwegian Medical Association (NMA)}

General Practioner (GP)

Hopkin's Symptom Check List with 5 items (SCL 5)

Maslach's Burnout Inventory (MBI)

Odds Ratio (OR)

Confidence Interval (CI)

Non significant (ns)

\section{Competing interests}

The author(s) declare that they have no competing interests.

\section{Authors' contributions}

KIR has had the main responsibility for this manuscript, with study design, development of the questionnaire used, data collection with analysis and interpretation and manuscript development.

TG has contributed to study design, development of the questionnaire used, to data analysis and interpretation and to manuscript development.

$\mathrm{OA}$ is responsible for data collection of the comparison sample, has participated in constructing the specific questionnaire used, and has contributed to manuscript revision.

All authors read and approved of the final manuscript.

\section{Acknowledgements}

We thank The Norwegian Women's Public Health Association and Modum Bad for financial support. We also thank Per Vaglum and Reidar Tyssen at the Department of Behavioural Sciences in Medicine, University of Oslo for substantial and valuable comments during manuscript revision.

\section{References}

I. Firth-Cozens J, Greenhalgh J: Doctors' perceptions of the links between stress and lowered clinical care. Social Science \& Medicine 1997, 44(7): 1017-22.

2. King MB, Cockcroft A, Gooch C: Emotional distress in doctors: sources, effects and help sought. J $R$ Soc Med 1992, 85(10):605-608.
3. Falkum E: What is burnout? [in Norwegian: Hva er utbrenthet?] Tidsskrift for Den Norske Laegeforening 2000, I 20( I 0): I I 22-8.

4. Tyssen R, Vaglum P: Mental health problems among young doctors: an updated review of prospective studies. [Review] [63 refs]. Harvard Review of Psychiatry 2002, 10(3): $154-65$.

5. Firth-Cozens J: Depression in doctors. In Depression and physical illness Edited by: Robertson MM, Katona CLE. New York: John Wiley \& Sons Ltd; I997:95-III.

6. Wall TD, Bolden RI, Borrill CS, Carter AJ, Golya DA, Hardy GE, Haynes CE, Rick JE, Shapiro DA, West MA: Minor psychiatric disorder in NHS trust staff: occupational and gender differences. British Journal of Psychiatry 1997, 171:519-23.

7. Hem E, Haldorsen T, Aasland OG, Tyssen R, Vaglum P, Ekeberg O: Suicide rates according to education with a particular focus on physicians in Norway 1960-2000. Psychological Medicine 2005, 35(6):873-80.

8. Lindeman S, Laara E, Hakko H, Lonnqvist J: A systematic review on gender-specific suicide mortality in medical doctors. British Journal of Psychiatry 1996, 168(3):274-9.

9. Taylor C, Graham J, Potts HW, Richards MA, Ramirez AJ: Changes in mental health of UK hospital consultants since the mid1990s. Lancet 2005, 366(9487):742-4.

10. Rosvold EO, Bjertness E: Illness behaviour among Norwegian physicians. Scandinavian Journal of Public Health 2002, 30(2): $125-32$.

II. Kivimaki M, Sutinen R, Elovainio M, Vahtera J, Rasanen K, Toyry S, Ferrie JE, Firth-Cozens J: Sickness absence in hospital physicians: 2 year follow up study on determinants. Occupational \& Environmental Medicine 200I, 58(6):36I-6.

12. Ingstad B, Christie VM: Encounters with illness: the perspective of the sick doctor. Anthropology \& Medicine 200I, 8(2/3):20I-2I0.

13. Tyssen R: The physician-patient relationship when the patient is a physician. [in Norwegian: Lege-pasient-forholdet når pasienten også er lege]. Tidsskr Nor Laegeforen 200I, I 2 I (30):3533-3535.

14. Davidson SK, Schattner PL: Doctors' health-seeking behaviour: a questionnaire survey. Med J Aust 2003, I79(6):302-305.

15. Rosvold EO, Bjertness E: Physicians who do not take sick leave: hazardous heroes? Scandinavian Journal of Public Health 200I, 29(I):7I-5.

16. Centrella $M$ : Physician addiction and impairment-current thinking: a review. [Review] [3/ refs]. Journal of Addictive Diseases 1994, I3(1):9I-105.

17. Nelson HD, Matthews AM, Girard DE, Bloom JD: Substanceimpaired physicians probationary and voluntary treatment programs compared. West J Med 1996, 165(I-2):3I-36.

18. Aasland OG: Hospital modernista. [in Norwegian]. Tidsskrift for Den Norske Laegeforening 200I, I 2 I (30):3638-9.

19. Roness A, Kaldestad E: Mental disorders among physicians hospitalized in a psychiatric clinic. [in Norwegian Psykiske lidelser hos leger innlagt $i$ en psykiatrisk klinikk]. Tidsskr Nor Laegeforen 1991, I I I (30):3619-3622.

20. Silvester S, Allen H, Withey C, Morgan M, Holland WW: The provision of medical services to sick doctors. A conspiracy of friendliness? In A study by the Department of public health medicinc UMDS St. Thomas Campus Edited by: Mitchell D, Ledingham J, AshleyMiller M. Burgess (Abingdon) Ltd, London; 1994.

21. Pitt E, Rosenthal MM, Gay TL, Lewton E: Mental health services for residents: more important than ever. Acad Med 2004, 79(9):840-844.

22. Matthews DA, Classen DC, Willms JL, Cotton JP: A program to help interns cope with stresses in an internal medicine residency. J Med Educ 1988, 63(7):539-547.

23. McCue JD, Sachs CL: A stress management workshop improves residents' coping skills. Arch Intern Med 1991, I 5 I (I I ):2273-2277.

24. Mushin IC, Matteson MT, Lynch EC: Developing a resident assistance program. Beyond the support group model. Arch Intern Med 1993, I 53(6):729-733.

25. Aasland OG, Olff M, Falkum E, Schweder T, Ursin H: Health complaints and job stress in Norwegian physicians: the use of an overlapping questionnaire design. Social Science \& Medicine 1997, 45(II): 1615-29.

26. Gude T, Vaglum P, Tyssen R, Ekeberg O, Hem E, Rovik JO, Finset $K$, Gronvold NT: Identification with the role of doctor at the end of medical school: a nationwide longitudinal study. Medical Education 2005, 39(I):66-74. 
27. Sutherland VJ, Cooper CL: Job stress, satisfaction, and mental health among general practitioners before and after introduction of newcontract. BMJ 1992, 304(684I): I 545-8.

28. Tyssen R, Vaglum P, Gronvold NT, Ekeberg O: The impact of job stress and working conditions on mental health problems among junior house officers. A nationwide Norwegian prospective cohort study. Medical Education 2000, 34(5):374-84.

29. Maslach C, Jackson SE: The measurement of experienced burnout. Journal of Occupational Behavior I98I, 2:99-II3.

30. Tambs K, Moum T: How well can a few questionnaire items indicate anxiety and depression? Acta Psychiatr Scand 1993, 87(5):364-367.

3I. Sandanger I, Moum T, Ingebrigtsen G, Sorensen T, Dalgard OS, Bruusgaard D: The meaning and significance of caseness: the Hopkins Symptom Checklist-25 and the Composite International Diagnostic Interview. II. Soc Psychiatry Psychiatr Epidemiol 1999, 34(I):53-59.

32. Paykel ES, Myers JK, Lindenthal JJ, Tanner J: Suicidal feelings in the general population: a prevalence study. British Journal of Psychiatry 1974, I 24(0):460-9.

33. Shanafelt TD, Bradley KA, Wipf JE, Back AL: Burnout and selfreported patient care in an internal medicine residency program. Ann Intern Med 2002, I 36(5):358-367.

34. West CP, Huschka MM, Novotny PJ, Sloan JA, Kolars JC, Habermann TM, Shanafelt TD: Association of perceived medical errors with resident distress and empathy: a prospective longitudinal study. JAMA 2006, 296(9): 107|-1078.

35. Gerrity MS: Interventions to improve physicians' well-being and patient care: a commentary. Social Science \& Medicine 2001, 52(2):223-5.

36. Toyry S: Burnout and self-reported health among finnish physicians. In Department of Medical Sciences PhD-thesis. Kuopio university publications; 2005:365.

37. Hsu K, Marshall V: Prevalence of depression and distress in a large sample of Canadian residents, interns, and fellows. American Journal of Psychiatry 1987, I 44( I 2): I56 I-6.

38. Tyssen R, Rovik JO, Vaglum P, Gronvold NT, Ekeberg O: Help-seeking for mental health problems among young physicians: is it the most ill that seeks help? - A longitudinal and nationwide study. Social Psychiatry \& Psychiatric Epidemiology 2004, 39( 12 ):989-93.

39. Grassi L, Magnani K: Psychiatric morbidity and burnout in the medical profession: an Italian study of general practitioners and hospital physicians. Psychotherapy \& Psychosomatics 2000, 69(6):329-34

40. Olkinuora M, Asp S, Juntunen J, Kauttu K, Strid L, Aarimaa M: Stress symptoms, burnout and suicidal thoughts in Finnish physicians. Social Psychiatry \& Psychiatric Epidemiology I990, 25(2):8|-6.

4I. Davis DA, Mazmanian PE, Fordis M, Van Harrison R, Thorpe KE, Perrier L: Accuracy of physician self-assessment compared with observed measures of competence: a systematic review. JAMA 2006, 296(9): I094-II02.

\section{Pre-publication history}

The pre-publication history for this paper can be accessed here:

\section{http://www.biomedcentral.com/1471-2458/7/36/prepub}

Publish with Biomed Central and every scientist can read your work free of charge

"BioMed Central will be the most significant development for disseminating the results of biomedical research in our lifetime. "

Sir Paul Nurse, Cancer Research UK

Your research papers will be:

- available free of charge to the entire biomedical community

- peer reviewed and published immediately upon acceptance

- cited in PubMed and archived on PubMed Central

- yours - you keep the copyright
BioMedcentral 